\title{
CROMATISMO EM AS IMPUREZAS DO BRANCO
}

\section{Denise Azevedo Duarte Guimarães *}

As cores sempre tiveram e têm significado para o ser humano. Considesando que a cor é o choque entre a luz e treva, as cores revelam, em seus matizes, ora o predomínio de uma, ora de outra. As mais luminosas, mais claras, chamam-se cores quentes; as mais frias sāo as menos luminosas e mais escuras. As conotações de alegria pertencem às cores claras, enquanto a tonalidade escura ć tristc. São míticos os conceitos de que das trevas saem os perigos e da luz sai a vida, a tranqüilidade.

Os estudos sobre a luta entre as trevas e a luz são encontrados na cultura alexandrina, entre os gnósticos egípcios e em todos os conhecimentos iniciáticos das culturas superiores.

A obra de Carlos Drumond de Andrade, neste sentido, revela o espaço clesta luta incessante entre o claro e o escuro, onde o cromatismo configura $c$ universo poético do personagem "gauche".

O presente trabalho pretende, a partir do estudo dos referentes cromáticos em As Impurezas do Branco, constatar uma etapa altamente significativa na obra de Carlos Drummond de Andrade: o momento em que claro $=$ tese, $\mathrm{e}$ escuro = antítese, integram-se numa sintese vital restauradora.

As conclusões atingidas apoiam-se no seguinte levantamento:

\section{Referentes cromáticos}

\subsection{Cores}

$\begin{array}{llrl}\text { Verde } & - & 10 \text { vezes } \\ \text { Branco } & - & 9 \text { vezes } \\ \text { Azul } & - & 7 \text { vezes } \\ \text { Dourado } & - & 3 \text { vezes } \\ \text { Negro } & - & 2 \text { vezes }\end{array}$

- Denise Azevedo Duarte Guimarães licenciou-se em Letras pela Universidade Federal do Paraná em 1973. Neste mesmo ano iniciou a sua colaboraçāo na imprensa local, sobretudo na coluna "Portugaliae", onde publicou: As imagens aquáticas na poética de António Nobre, Antônio Nobre e o repúdio do circunstancial, Medo e esperança na Manhä submersa, Abelaira e a reconquista do universo através da palavra. Na revista Letras publicou A zoomorfizaçăo em Antonio Chimango (n. 23, 1975) e Perspectiva, narrativa e estatuto do personagem Brás Cubas (n. 24, 1975). Atualmente, exerce as funçōes de Auxiliar de Ensino de Literatura Brasileira no Departamento de Linguística, Letras Clássicas $\theta$ Vernáculas e de Coordenadara do Centro de Estudos Brasileiros da Universidade Federal do Paraná. 
GUIMART̃ES, D. A. D. Cromalismo em as impurezas do branco

$\begin{array}{llll}\text { Cinza } & - & 2 & \text { vezes } \\ \text { Vermelho } & - & 2 \text { vezes } \\ \text { Rosa } & - & 2 \text { vezes } \\ \text { Amarelo } & - & 1 \text { vez } \\ \text { Marrom } & - & 1 \text { vez } \\ \text { Prateado } & - & 1 \text { vez } \\ \quad \text { Violeta } & - & 1 \text { vez } \\ & - & 10 \text { vezes } \\ 1.2 \text { Sugestões cromáticas } & - & 8 \text { vezes } \\ 1.3 \text { Palavra Cor (es) } & - & 2 \text { vezes }\end{array}$

2. Criaçōes vocabulares com efeitos cromáticos -3

3. Cores como epítetos:

3.1 redundantes -6 vezes

3.2 necessários -9 vezes

4. Topologia do referente cromático: anteposto ao substantivo -8 vezes posposto ao substantivo -8 vezes

5. Efeitos cromáticos especiais:

5.1 Transposição de planos -11 vezes

5.2 Sinestesias -21 vezes

5.3 Correspondências -14 vezes

6. Fluxo - claro/escuro:

6.1 Luz (ou sugestāo luminosa pura) - 11 vezes

6.2 Sombra pura -0 (nenhuma vez)

6.3 Efeito antitético -12 vezes

A partir deste levantamento, estudando cada caso em particular, no todo do livro e no relacionamento com os livros anteriores, pudemos inferir uma série de colocações a respeito deste conjunto de poemas.

"COMUNICAÇAO

AMAR

DIVINDADE

As "matérias" do livro:

$\begin{array}{ll}\text { PERSONA } & \text { VIVER } \\ \text { PROBLEMATIZAR } & \text { MORRER } \\ \text { QUIXOTES } & \text { ARTISTAS } \\ \text { BRASIL } & \\ \text { UMA CASA" } 1 & \end{array}$

são idéias tecidas a partir das três bases físicas do fenômeno estético:

- o mundo das formas

- o mundo das cores

- o mundo dos sons.

Atendo-nos ao mundo das cores, verificamos seu inter-relacionamento rerfeito com os demais nesta obra, onde o lúdico é um meio de atingir o estético.

I DRUMMOND DE ANDRADE, Carlos. As impurezas do branco. Río de Janeiro, J. Olymplo, 1974. p. 3. (Todas as citaçōes de poemas correspondem à esta ediçăo). 
Num livro onde o branco serve de título, para analisarmos os referentes cromáticos devemos considerar alguns pressupostos básicos:

1:- O significado simbólico das cores varia conforme a cultura e os autores.

$2^{\circ}$ - Confrontando-se os estudos de Wirth e Papus, que representam uma síntese da simbologia das escolas esotéricas; aos de Pfister e Vilemor Amaral, que sintetizam as teorias psicológicas sobre o assunto 2 , pode-se verificar uma concordância em relação a determinadas cores, justamente as mais importantes na estrutura da obra analisada:

\section{Simbologia das cores (adaptação)}

\section{Teorias esotéricas}

Vermelho princípio animador

Verde natureza, fluido vital

Preto nada, morte

Branco sintese, pureza, o absoluto

\section{Teorlas psicológicas}

descargas agressivas bruscas

busca de adaptação afetiva

sofrimento, frustraçāo

paz (símbolo universal)

3. - A dificuldade em estabelecer se há alguma intencionalidade de simbolizante na escolha destas cores, no caso de Drummond, minimiza-se por ser ele aquele que "luta com as palavras" conscientemente, um poeta que atingiu o refinamento técnico ao nível da seleção dos componentes do discurso.

o branco, referente cromático que desde o título apresenta-se como elemento estruturante do espaço textual, aparece 9 vezes. Vejamos alguns exemp!os:

Sofrendo reiteração quartenária no $20^{\circ}$ verso do poema "Tiradentes", o sintagma branca é repetido pela quinta vez no $40^{\circ}$ verso. A repetição, forma cie amplificação temática, valoriza o elemento ponderal do poema, multiplicando-o. Sendo o germe da antítese, a quintupla repetição gera uma tensão especial no poema, intensificada pelo aparecimento, no $60^{\circ}$ verso, do sintagma rubra. Por sua vez, a tonalidade vermelha sofre reiteração sinonímica no 7. verso através do sintagma sangue.

Altamente sinestésica se torna esta primeira unidade de sentido do poema, apresentando termos plásticos de grande efeito visual no $6 .^{\circ}$ e $7 .^{\circ}$ versos:

\section{Tiradentes}

(com muita honra)

1 - Bandeira de uma república visionária

2 - branca branca branca branca

3 - república nunca proclamada

4 - branca

2 WEIL Pierre. Esfinge; estrutura e mistério do homem. Petrópolis, Vozes, 1973. p. 129. 
GUIMARAES, D. A. D. Cromatismo em as impurezas do branco

5 - rubra

6 - do sangue do único republicano

7 - em triângulo multiângulo de membros repartidos.

(fragmento) (p. 79)

Observe-se a contaminaçāo semântica de "sangue" para "membros reparticos" - sinestesia pura. O eco "em triângulo multiângulo" reelabora a conformação geométrica da bandeira, completando a visualização iniciada pclos referentes cromáticos. Ao mesmo tempo. metaforicamente, remete à agudeza dos ângulos. Merece destaque a contaminação semântica no primeiro espaço (versos 1 a 4) - o espaço da visāo. da utopia - onde os sintagmas "república visionária" e "nunca proclamada" reiteram a negaçāo da paz, encontradiça na liberdade, que o branco simbolizaria Atmosfera antitética, portanto. que prepara a brusca transposiçāo para o espaço de Tanatos, de branca para rubra, onde os referentes cromáticos como que materializam o sangrento sacrificio.

A reiteração da cor branca, portanto, vai num crescendo, ampliando o espaço da utopia - articulado por Eros - até que, bruscamente a aguda rcalidade transparece, no espaço articulado por Tanatos:

Plano utópico

Plano real

branca branca branca branca branca

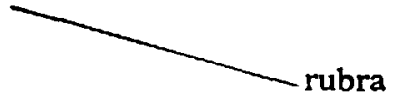

sangue

membros repartidos

A cada repetição a "brancura" se acentua até atingir seu máximo esplencor, momento em que se tinge do rubro do sangue derramado.

Efeitos cromáticos. aliados aos plásticos, sonoros e semânticos, configuI am a imagem da bandeira no lugar do herói verdadeira síntese emocional.

Entre outros casos do aparecimento da cor branca, observamos:

"tua branca alegria de viver a vida universal" (p. 93) confrontando-o com:

"a alegria colorida da libertaçäo" (p. 96)

A partir co substantivo abstrato alegria, verificam-se duas transposiçōes de planos, intimamente relacionadas.

Concretizando-a primeiramente branca, o poeta refere-se à alegria de viver. Neste caso, o referente cromático antepōe-se ao substantivo, o que vai fazer com que o tom emocional predomine e a tal ponto, que o adjetivo torna-se mais forte que o substantivo, intensificando-se suas conotaçōes.

No 2.0 caso, concretizando a abstraçāo "alegria" como colorida o adjetivo proposto impregna o substantivo de toda a multiplicidade de corés, numa reiteraçāo que poderíamos considerar sinonímica (nāo é alegre tudo que ¿ colorido? Não seria a libertaçāo uma alegria suprema?)

Neste caso, a posiçāo enclítica do adjetivo faz predominar a sensação visual c descritiva. 
Pelos exemplos, podemos perceber que a topologia do referente cromático não é aleatória.

No poema "Declaração em juízo" (p. 26-9) o branco aparece como síntese da cosmovisão poética de Carlos Drumond de Andrade. Neste balanço da vida que não viveu "senão em projeto", pois "a verdadeira vida sorria longe, indecifrável", o poeta constata a indiferença do mundo diante de sua sofrida confissão. Indiferença esta que o conduz à sintese da oposição Tudo/Nada - insistentemente tematizada em livros anteriores. Conclui dizendo:

"............. é tudo a mesma

nenhuma coisa, e branca". (p. 29)

Temos pois o tudo que é nada (nenhuma coisa) concretizado na cor branca, que é também a síntese de todas as cores.

Neste sentido, é interessante lembrar a excelente tese onde Affonso Romano de Sant'Anna, estudando a dialética Tudo/Nada nas obras anteriores de Drummond, afirma: "sua poesia é um processo de concretização do Nada". 3

Os conflitos Poeta/Mundo conduziram ao conhecimento do Nada que habita o Tudo, dando ao poeta condição de resolvê-los, na última etapa de sua trajetória, o que Impurezas do Branco confirma.

$\mathrm{Na}$ mútua informação quantidade e qualidade, processa-se a integração da dialética evidenciada.

Por outro lado, o negro, aparecendo apenas duas vezes em todo o livro. $\mathbf{r m}$ configurar a quase supressāo das manifestações dos movimentos turvos do eu profundo, nesta fase. No $10^{\circ}$ caso, descrevendo a "maldição do esflêndido verāo" (p. 118) num poema carregado de antíteses, o referente (romático negro vem concretizar a imagem do próprio inferno (=averno), associado a outros sintagmas do mesmo campo semântico:

"sobe do negro chão meloso e espedaçado

o súlfur dos avernos em pescoçōes de fogo" (p. 118)

Observe-se os efeitos sinestésicos, ferindo simultaneamente visāo, tato e olfato.

No caso, a anteposiçāo do referente cromático, havendo inclusive outros adjetivos, vem reforçar a carga simbólico-emocional da cor negra.

No 2. caso, "Motivos de Bianco", poema altamente plástico a partir do tema, o referente cromático negro é utilizado numa transposição para o F.lano abstrato:

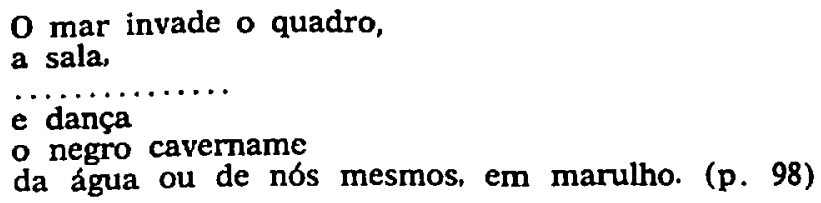

3 SANT'ANNA, Affonso Romano de. Drummond, o gauche no tempo. Rio de Janeiro, LIA/INL, 1972. p. 241. 
Imagens oníricas da trágica submersão nas profundezas do "eu" (=negro cavername), trazem toda a carga simbólica negativo do elemento cromático negro, associada aos elementos dinâmicos na expressāo dos movimentos turvos do mais profundo do ser em conflito. Mais uma vez a anteposição do adjetivo reforça a carga emocional.

E interessante notar que, no livro analisado, o branco e o negro vêm srmpre antepostos ao substantivo, sendo que as demais cores, pospostas. Tal constatação permite afirmar a supremacia das duas cores citadas sobre as demais, o que será posteriormente estudado quando nos referirmos ao fluxo claro/escuro.

No excmplo acima, podemos observar as imagens aquáticas, recorrentes ne obra do autor e no livro analisado. Observamos uma insistência na toralidade verde do mar. Sendo o referente cromático mais freqüente no livro, $r$. verde associado às imagens aquáticas, é mais significativo. Temos uma situação poética aparentemente idêntica à analisada anteriormente (Motivos de Bianco" - a temática da submersão), no poema "O Mar no living":

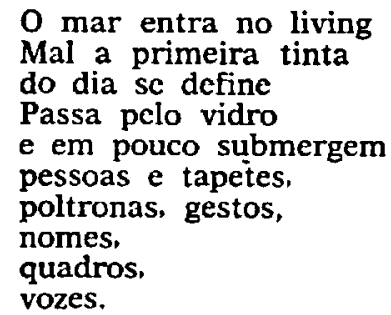

(fragmento - p. 114)

Novamente a imagem da invasão das águas, porém num sentido diferente. Lembrando que o simbolismo das águas implica tanto Morte como Re-nascença, vemos reforçado o sentido de travessia na obra de Carlos Drummond de Andrade. Nas mitologias, a dissoluçāo é sempre seguida de um novo nascimento.

No poema analisado, como em outros de livros anteriores, a invasão das águas configura o mito do dilúvio, não no sentido da extinção definitiva, mas no de uma nova criação, nova vida, evidente nos versos:

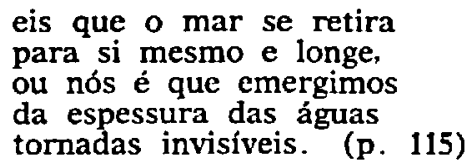

Convém lembrar, que na poética drummondiana, mar=tempo é algo interior que surge sempre como um enígma ameaça ou dúvida. $O$ sentido de fluxo temporal, recorrente na obra, bem claro se torna cm versos como:

O mar chega de volta

mal a primeira tinta

se define, do dia (p. 115) 
No fluxo/refluxo, perenc imersão/emersão, o mar=tempo permanece alheio a "todo mobiliário e pessoas, imersos", prosseguindo no

balouçante estar sozinho e verde verdisozinho imenso em pura escuridāo. (p. 115)

No exemplo, os referentes cromáticos compõem a imagem reiterada do mar-tempo-eternidade (morte?).

A criaçāo vocabular "verdisozinho" enfatiza a carga semântica dos sintagmas do verso anterior, aliando-se ao epiteto redundante "imenso" na configuração da extensão do enígma que "pura escuridão" sugere. (E interessante observar o cfeito claro/escuro em todo o poema).

0 verde-mar aparece ainda em "Diamundo" compondo imagem onírica:

Nasce em Bogotá um menino

inteiramente verde-mar. (p. 19)

E um poema longo, onde as manchetes dos jornais transformam-se no material poético. Os dois versos citados são os últimos, constituindo-se num climax para a visāo da realidade que nos cerca, cujo aspecto surreal fica assim evidenciado.

Nos demais casos, o referente cromático verde aparece como epíteto redundante ou necessário; utilização remanescente da atitude espontaneamente mimética de fases anteriores do poeta.

Ainda com relaçāo ao verde, observa-se outra criação vocabular "verdinatais", no poema, "Pintura de Wega":

A tona do mundo irrompem

os mundos de Wega

violentos

verdinatais, vermelhoníricos. (p. 102)

Pıntura tensa - motivação de uma linguagem poética que procura compor um mundo maravilhoso através da montagem de novos vocábulos:

verdinatais - conotaçāo de festas

vermelhoníricos - bruscas descargas agressivas.

Contraste cromático, carga antitética das conotaçōes, intensificação da antítese a partir da anteposição do sintagma "violentos", tudo isso vem confirmar a carga altamente tensa dessa pintura que o poeta pretende plasticamente sugerir.

No conjunto de poemas a palavra cor (es) que aparece 8 vezes (ao lado cie colorido (a) -2 vezes) vern dar relevo especial ao cromatismo. Nos versos abaixo, remete ao plano do maravilhoso:

Assim Bianco, viajando

a cor e seus compartimentos encantados. (p. 99)

Das sugestōes cromáticas registradas, ressalte-se o visualismo do poema " $\mathrm{Li}$ vraria", onde o verso "Aquário de aquarelas" (p. 116) alia a sugestão cro- 
mática à aliteração e ao timbrc aberto da vogal a. Temos uma associação de aspectos fónicos e óticos, na fixaçāo da fluidez do colorido.

Outros casos de transposição de planos são freqüentes, merecendo destaque os seguintes:

$$
\begin{aligned}
& 10^{\circ} \text { - "o azul pureza" (p. 95) } \\
& 20^{\circ} \text { - "o verde cantante" (p. 95) } \\
& 3 .^{\circ} \text { - "o rumor sem verdes" (p. 87) } \\
& \text { 4. - "luz violeta". (p. 88). }
\end{aligned}
$$

No 1." caso, observamos uma migraçāo de classe, quando o referente cromático passa a ser substantivo, qualificado por um substantivo abstrato. $O$ estranhamento produz efeitos altamente sugestivos.

O 2.0 caso é semelhante ao $10^{\circ}:$ o substantivo verde é antropomorficamente caracterizado "cantante". Ambos os exemplos são do poema "Brasil Tarsila". onde $o$ pocta consegue atribuir novos valores cromáticos às coisas, numa sintese apreendida pelo espírito através da enumeraçāo concreta das tonaliciades. Para sugerir cromaticamente o outro lado da vida, o poeta estrutura o infinito em tonalidades suaves:

\section{prazer dos olhos meus onde te encontres} azul c rosa e verde para sempre (p. 97).

O 3." e o 4." casos estāo no poema "O Poeta irmāo". Em Rumor sem verdes, através da sugestão sonoro-cromática, ampliam-se as conotaçōes da "permanência" do amigo morto.

Permanência esta que se consubstancia na luz violeta = saudade. Lembrando a simbologia do Verde $=$ fluido vital e do violeta $=$ misticismo. podemos perceber que o poema ađquire nova dimensāo ligada às teorias espiritualistas.

Cores, sons, formas, tudo se associa na configuraçāo do universo poćtico drummondiano.

As correspondências baudelaireanas encontram seu lugar de destaque no livro analisado:

$$
\begin{aligned}
& \text { sinfonia de letras } \\
& \text { e cores enlaçadas } \\
& \text { No silêncio dos livros } \\
& \text { abertos em gravura. (p. 116). }
\end{aligned}
$$

Cbserve-se a antítese "sinfonia/silèncio", onde as "cores enlaçadas" harmonizam o conjunto. Temos som + cor + forma, fórmula que se repete em:

$$
\begin{aligned}
& \text { subo ao céu em foguete } \\
& \text { até a prima solidão } \\
& \text { levando o som } \\
& \text { a cor o pavilhão. (p. 6). }
\end{aligned}
$$

Vale dizer, na comunicação (os 2 poemas, a que os 2 exemplos acima pertencem, remetem ao mesmo tema) a correspondência entre as três bases físicas do fenômeno estético é a fórmula ideal. 
Ainda o mesmo esquema em:

Fayga faz a forma

flutuar e florir na pauta

musicometálica.

Agua forte, água tinta

água fina. (p. 100).

Conotando cor, o sintagma "florir" alia-se ao som e a forma. repetindo-se no inesmo poema:

No coro de cores, cor

ressoando nas coisas, independente do som. (p. 100)

A aliteração acentua as conotações, desenvolvendo-se o poema em torno das correspondências, para culminar em:

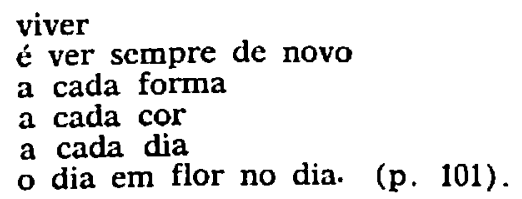

O espaço articulado por Eros salienta uma nova visão de mundo, que neste livro se revela em toda sua plenitude: a idéia de que o essencial é viver como c dia que irrompe das trevas.

Neste sentido, é importante analisarmos o desenvolvimento do fluxo claro/escuro no presente estágio da poética de Carlos Drummond de Andrade.

Em As Impurezas do Branco, temos uma passagem do predomínio do escuro (obras anteriores) para a supremacia da luz. A luz aparece em todo seu esplendor 11 vezes, sendo que a sombra jamais aparece isolada. E significativa tal constatação.

A contraposiçāo claro/escuro revela-se o eixo imagístico em torno do qual harmonicamente a obra se desenvolve. Aparecendo 12 vezes, o efeito luz/sombra impõe-se como imagem continuada, na reiteração das antíteses fundamentais do livro.

Branco e negro, originalmente em seu sentido simbólico básico, vão adensando uma significação na trajetória da poética de Carlos Drummond de Andrade, para, a partir de Claro Enigma se transformar nos dois polos: vida/morte.

Em As Impurezas do Branco, cristaliza-se tal significado como índice do conflito existencial praticamente resolvido.

$\mathrm{Na}$ configuração dos sentimentos, não mais uma atitude mimética e sim a manipulação das cores de modo mais subjetivo espécie de projeção expressionista dos conflitos intimos. Passando o cromatismo a ter um significado mais profundo, claro/escuro modelizam a estrutura dinâmica de polos que se atraem, ganhando a obra em organicidade:

Vai comigo meu projeto

entre sombras, minha luz

de bolso me orienta. (p. 104). 
O poeta faz transparecer na escuridão, sempre uma luz, nas trevas resta sempre a esperança da luz de um novo dia. Esta luz associa-se à vida, ao amor:

E isto, amor: o ganho não previsto.

o prêmio subterrâneo e coruscante,

leitura de relámpago cifrado, (p. 36).

A sugestão luminosa na cscuridāo (=subterrâneo) revela a insistência da vida=amor em permanecer. A sensação do fluxo temporal espelha-se na alternância cromática. Não mais conflituosamente, claro/escuro se integram; ainda que se opondo, se perfazem.

O personagem "gauche". ciesde suas origens habituado às sombras, dcsenvolve sua trajetória a partir destas até atingir outro espaço cromático. Alcança a luz, integra-se, mergulha no branco - embora consciente de suas impurezas.

O personagem, que começou sua caminhada sob a ćgide de "um anjo destes que vivem nas sombras"; atinge a maturidade deixando-se envolver pela luz. O conflito entre a norma do dia e a paixāo pela noite, característico de suas fases anteriores, resolve-se no predomínio da claridade. Claridade esta que impõe a contemplação da realidade humana sob a perspectiva de uma vida infinda. Os versos que o poeta dedica a Manuel Bandeira, sintetizam esta nova visāo de mundo:

Sua poesia pousa no tempo.

Cada verso, com sua música

e sua paixão, livre de dono,

respira em flor, expande-se

na luz amorosa. (p. 91).

\section{REFERENCIAS BIBLIOGRAFTCAS}

BACHELARD, Gaston La poétique de l'espace. Paris, Presses Universitaires de France, 1967. $214 \mathrm{p}$.

BALLY, Charles. Traité de stglistique Prançaise. 3. ed. Paris, Klincksiek, 1951 v. 2. DRUMMOND DE ANDRADE, Carlos. As impurezas do branco. Rio de Janeiro, J. Olympio, 1974 . $126 \mathrm{p}$.

- Poesia completa e prosa. Rio de Janeiro, Aguilar, 1973. 1315 p.

Eltade, Mircea. Aspects du mythe. Paris, Gallimard, 1963. 247 p.

SANT'ANNA, Affonso Romano de. Drummond, o gauche no tempo. Rio de Janeiro, LIA/INL, 1972. $286 \mathrm{p}$.

WEIL, Pierre. Esfinge; estrutura e mistério do homem. Petrópolis, Vozes, 1973. 207 p.

\section{Resumo}

O estudo dos referentes cromáticos no livro As Impurezas do Branco objetiva constatar uma etapa significativa na obra de Carlos Drummond de AnCrade: o momento em que claro=tese e escuro=antitese integram-se numa síntese vital restauradora. Neste momento em que o poeta alcança a luz, mergulha no branco - embora consciente de suas impurezas. Nāo mais uma 
atitude mimética na configuração dos sentimentos, e sim, a manipulação das cores de modo subjetivo, permite constatar que o cromatismo passa a ter um significado mais profundo.

\section{Résumé}

L'étude des afférents chromatiques dans le livre As Impurezas do Branco a par object constater une ćtape significative chez Carlos Drummond de Ancirade: le moment où le clair=thèse et le sombre=antithèse s'intègrent dans Lne synthèse vitale restauratrice. A ce moment-là, le poète atteint la lumière ct il se plonge dans le blanc, quoique conscient de ses impuretés. Il n'y a plus unc attitude mimétique dans la configuration de ses sentiments, mais plutôt une manipulation des couleurs d'une façon subjective, qui lui permet vérifier que le chromatisme passe a avoir une signification plus profonde. 